\title{
The Effect of Welding Parameters on the Corrosion Resistance of Austenitic Stainless Steel
}

\author{
Dávid Miklós Kemény ${ }^{1 *}$, Dorina Kovács \\ ${ }^{1}$ Department of Materials Science and Engineering, Faculty of Mechanical Engineering, Budapest University of Technology and \\ Economics, Müegyetem rakpart 3., 1111 Budapest, Hungary \\ * Corresponding author, e-mail: kemeny.david@gpk.bme.hu
}

Received: 19 November 2021, Accepted: 17 February 2021, Published online: 23 February 2022

\begin{abstract}
Electricity produced in power plants is essential in our everyday life. In general, the energy transfer takes place after processing the energy source in boilers or steam generators. Steam is generated through this process, that operates the turbines and they generate electricity through the generators. As such equipment operates in a high pressure, corrosive and high temperature environment, these circumstances may damage the tubes in the heat exchangers. Our research examines the potential of corrosion of heat exchanger tubes after welding. The typical corrosion process is pitting. The corrosion resistance of stainless steel depends on a protective, passive film formed on the surface of the steel exposed to the service environment. The use of fusion welding for fabrication leads to local variations in the chemical composition inside the material, which may significantly alter the stability of the passive layer and hence the corrosion behavior. The impact of welding parameters (shielding gas, amperage) was examined on corrosion resistance of X6CrNiTi18-10 austenitic stainless steel. The corrosion test was performed according to ASTM G48 standard. The weight loss was measured in Fe(III)-chloride solution by the first corrosion test. The results showed that the corrosion resistance of stainless steel was better at $50 \mathrm{~A}$ and $10 \mathrm{l} / \mathrm{min}$ welding parameters. During the second test, a potentiodynamic corrosion test was made, and the potentiodynamic curve was measured in $9 \%$ saline solution. In this solution, the stainless steel had a better corrosion property because it was measured in a less aggressive medium.
\end{abstract}

Keywords

X6CrNiTi18-10, welding, corrosion, ASTM G48, shielding gas, potentiodynamic curve

\section{Introduction}

There are many areas of application for stainless steel. It is preferred in the food and pharmaceutical industries but is also used in power plants [1]. The power plant use comes to the fore in this article. There are many types of power plants to generate electricity, for example, wind turbines, hydroelectric, thermal and nuclear power plants. The thermal and nuclear power plants use fossil fuels (which can be natural gas or uranium) [2]. From fossil fuel, energy is retrieved to generate steam in the generator and boilers. The saturated steam operates the turbines, and the turbines operate the generator to produce electricity.

The energy transfer goes by the corrosion resistant heat exchanger tubes. The condition for corrosion resistance is a stable, contiguous, passive layer on the steel surface. This is met when $\mathrm{Cr} \geq 12 \%$ and $\mathrm{C} \leq 1.2 \%$ [3-6]. This resistance is provided by the chromium-oxide $\left(\mathrm{Cr}_{2} \mathrm{O}_{3}\right)$ [7] on the surface of the steel if the amount of $\mathrm{Cr}$ is higher on the surface than inside of the material. The alloy needs to be homogeneous and contains appropriate $\mathrm{Cr}$ concentration to avoid rust formation. The stainless steel has high resistance to pitting, crevice and chloride stress corrosion cracking because of the passive surface film [8-10]. This passive film must be very thin, about $2-3 \mathrm{~nm}[3,11]$.

The heat exchangers could be damaged due to the high pressure and temperature during operation. It is possible to correct the failure by the repair welding of the heat exchanger tubes. It is important to repair the affected area to avoid the release of the heat transfer medium into the environment. This solution is possible at thermal power plants, but due to the high radiation level, it cannot be applied in nuclear power plants. The repair through welding is more favorable, as buying a new exchanger because it is more expensive. The passive layer may be damaged during welding; thus, the corrosion resistance of some 
parts of the weld seam may differ from the basic material $[12,13]$. Therefore, it is important to know the parameters of the welding in order to produce a sufficient quality weld seam with the highest corrosion resistance.

The aim of this research is to examine the effect of welding parameters on the X6CrNiTi18-10 austenitic stainless steel weldability. Different shielding gas and amperage were used during the welding to determine the optimum parameters for the best corrosion property.

\section{Materials and methods}

The tests were conducted on the X6CrNiTi18-10 (1.4541) austenitic stainless steel in the aspect of corrosion resistance. The typical chemical composition of $\mathrm{X} 6 \mathrm{CrNiTi18-10}$ stainless steel by weight percentage is: $\mathrm{C} \leq 0.08 \%$; Cr: $17-19 \%$; $\mathrm{Si} \leq 1 \% ; \mathrm{Mn} \leq 2 \%$; Ni: 9-12\%; $\mathrm{P} \leq 0.045 \% ; \mathrm{S} \leq 0.015 \% ; \mathrm{Ti} \leq 0.7 \%$ [14]. The corrosion resistance steel pipe was used with $40 \mathrm{~mm}$ diameter and $2 \mathrm{~mm}$ wall thickness. The filler wire was 316 . The welding equipment was Tungsten Inert Gas (TIG) and the shield gas was $100 \%$ Argon. The penetration depth is about 5-6 mm using the TIG welding [15]. Different parameters were used regarding the amperage and shield gas quantity for instance by welding procedure. The amount of shield gas was set to 6 or $101 / \mathrm{min}$, and in the case of each gas setting, the amperage was altered and set to 50 , 55 or $60 \mathrm{~A}$. The other parameters of weld have not been changed. The designation of the corresponding samples (shown in Fig. 1) and the applied welding parameters are listed in Table 1. Sludge formation and slag on the welded samples can be seen and Kor-Fel Px picking paste was used to remove the discoloration.

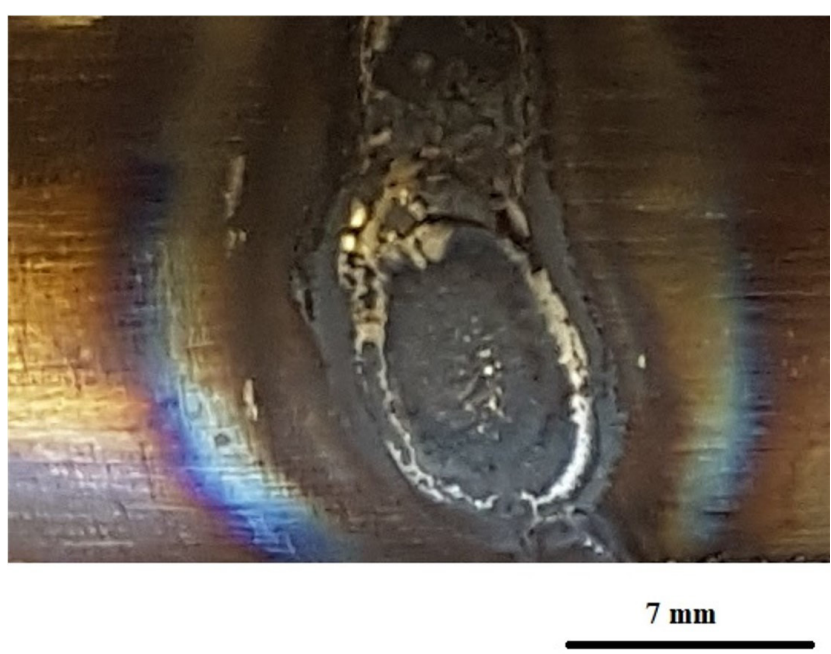

Fig. 1 The discolouration after weld on sample 2
Table 1 The identification of the samples and the varied welding parameters

\begin{tabular}{lcc}
\hline Sample & Shield gas $(1 /$ min $)$ & Amperage $(\mathrm{A})$ \\
\hline 1 & 6 & 50 \\
2 & 6 & 55 \\
3 & 6 & 60 \\
4 & 10 & 50 \\
5 & 10 & 55 \\
6 & 10 & 60 \\
\hline
\end{tabular}

The macroscopic images were taken with Olympus SZX16 stereomicroscope. The optical microscope inspection was performed by using an Olympus PMG 3 microscope. Kalling reagent was used to etch the surface to show the structure of the material. The ferrite content was measured with Fisher FMP30 ferritscope.

The first corrosion test was generated by following the ASTM G48-11(2020)e1 standard [16]. The 6\% Fe(III)chloride solution was used. The mass was measured with APX - 200 type precision balance (max $200 \mathrm{~g}$, measuring accuracy: $0.1 \mathrm{mg}$ ) after the corrosion test.

The second corrosion test was performed with Biologic SAS type SP-150 potentiostat. The solution was 9\% saline solution. The EDS (energy dispersive X-ray spectrometry) of Zeiss EVO MA10 scanning electron microscope was used to determine the atomic and weight percent of the corroded samples.

\section{Results and discussion}

Macrographs about the welded joint can be seen in Fig. 1. The discoloration in Fig. 1 is caused by $\mathrm{Cr}$ and Ni. As it is discernible, the amount of $\mathrm{Cr}$ and $\mathrm{Ni}$ were higher in the corrosion area (at the HAZ) than in the weld or base material. The main components of stainless steel are Fe, Ni and $\mathrm{Cr}$, so the main parts of these elements originate from the austenitic stainless steel [17].

The appearance of pitting after corrosion is clearly visible on the surface of samples in Fig. 2.

The ferrite content was determined in the welded joints and its immediate vicinity with ferritscope after welding. As it can be seen in Table 2, by using 10 1/min shield gas, the ferrite content was less than at the other (lower) shield gas quantity. The delta-ferrite can cause an increase in the sensitivity of hot cracking [18]. It has to be noted that no hot cracks were generated.

Table 2 shows the ferrite content of sample 4. This sample showed the least weight loss (Table 3). Corrosion tests 

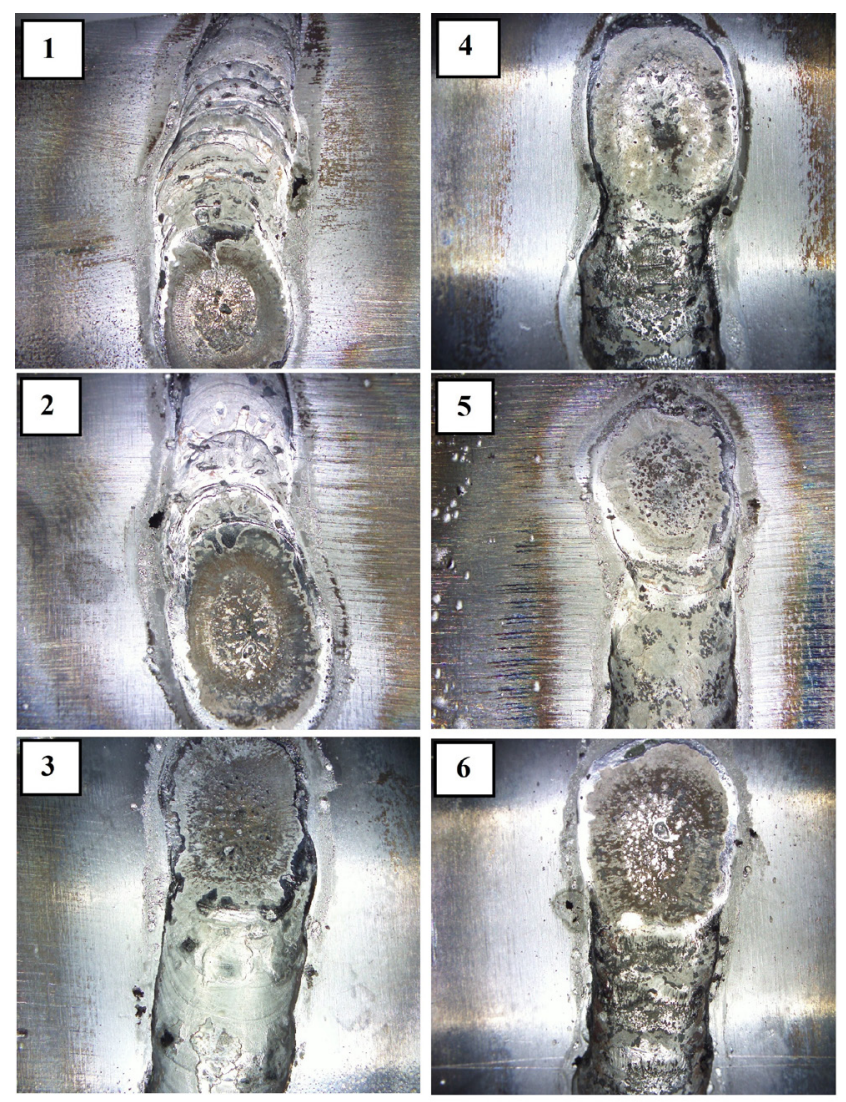

$4 \mathrm{~mm}$

Fig. 2 The welded samples after corrosion test

Table 2 The ferrite content (in percentage) of the samples at the welded joints

\begin{tabular}{lccccc}
\hline \multirow{2}{*}{ Sample } & \multicolumn{5}{c}{ Ferrite content (Ferrite number) } \\
& Material & HAZ & Weld seam & HAZ & Material \\
\hline 1 & 0.77 & 3.1 & 3.2 & 1.6 & 0.47 \\
2 & 0.46 & 1.3 & 3.6 & 2.8 & 0.42 \\
3 & 0.26 & 2.6 & 3 & 2.7 & 0.37 \\
4 & 0.3 & 1.9 & 2.3 & 2.8 & 0.34 \\
5 & 0.29 & 2.1 & 3.1 & 2.7 & 0.27 \\
6 & 0.43 & 1.4 & 2.2 & 1.6 & 0.34 \\
\hline
\end{tabular}

Table 3 The samples masses in the beginning and after 24 hours, and the corresponding weight losses

\begin{tabular}{lccc}
\hline \multirow{2}{*}{ Sample } & \multicolumn{2}{c}{ Mass $(\mathrm{g})$} & Weight loss $\left(\mathrm{g} /\right.$ year $\left./ \mathrm{cm}^{3}\right)$ \\
& 0. hour & 24. hour & 24.hour \\
\hline 1 & 18.8983 & 18.5292 & 5.73 \\
2 & 16.6738 & 16.3142 & 5.94 \\
3 & 14.9801 & 14.6136 & 7.35 \\
4 & 22.5622 & 22.1625 & 5.11 \\
5 & 16.0077 & 15.6329 & 6.47 \\
6 & 17.6556 & 17.2563 & 6.51 \\
\hline
\end{tabular}

were performed on the welded samples corresponding to the ASTM G48 standard [19]. The measured data are shown in Table 3.
The microstructure of X6CrNiTi18-10 austenitic steel can be seen in Figs. 3-4. The austenitic particles can be well distinguished, and the shaping lines are well observable after etching the base material with Kalling reagent, as shown in Fig. 3.

A typical cross-section of pitting corrosion in the base material is seen in Fig. 4. It shows the pitting of austenitic stainless steel X6CrNiTi18-10 resulting from insufficient corrosion resistance in a very aggressive chlorinated environment. The formation of pitting can be influenced by various parameters such as environment, chemical composition and metallurgical condition [20].

Corrosion is one of the typical damage processes regarding welded joints. The weight loss occurs in the welded joint, the seam and the base material and in the heat-effect zone (HAZ), which can be well observed in Fig. 5. Pitting was formed next to the weld joint typically in the HAZ (Fig. 4)

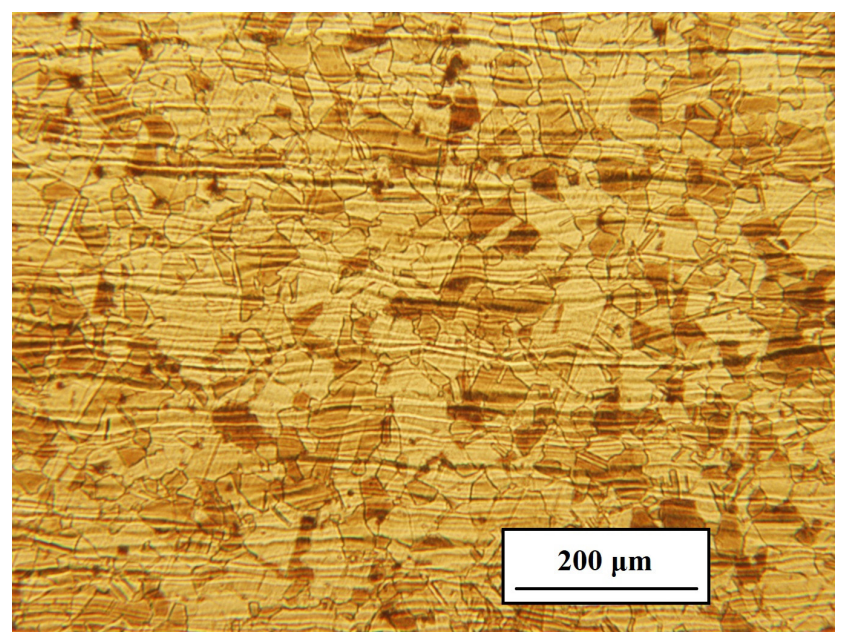

Fig. 3 Microstructure of austenitic stainless steel with the shaping lines

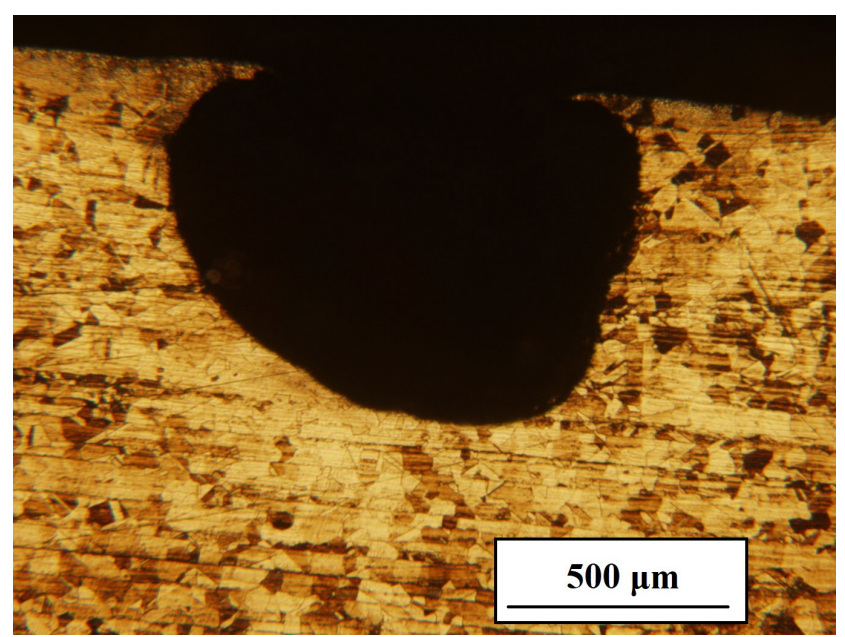

Fig. 4 Pitting in the basic material 


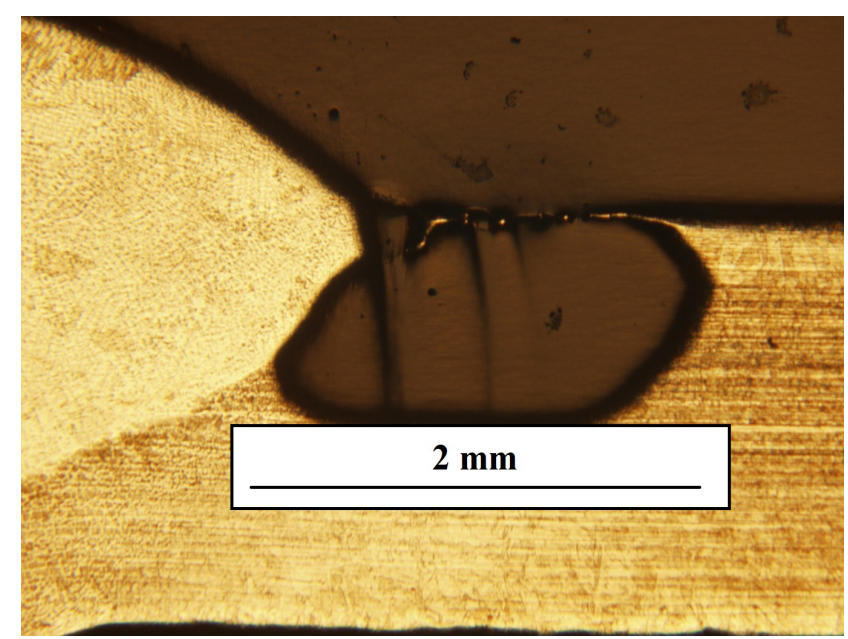

Fig. 5 Pitting in the HAZ next to the seam of the welded joint

The pitting is growing into the material, making a deep and windy hole under the surface, as shown in Fig. 6. That makes the pitting corrosion so dangerous because under the visual inspection cannot be seen all of the weight decreases, making the structure less resistant against the mechanical impacts. Ongoing investigations are needed to explore the pitting localization because predicting the pitting tendency is still complicated [21].

The HAZ and the delta-ferrite can be observed in Fig. 7 at higher magnification. Different welding parameters can be the shielding gas, heat input, the number of weld passes and the filler metal $[22,23]$. Uneven cooling results in areas with different chemical composition areas and weaker corrosion resistance.

It is important to note that large amounts of titanium can cause excessive stabilization, causing rust and iron oxide [24] on the surface of stainless austenitic steels. The typical appearance of titanium nitride (TiN) is seen in Fig. 8 [25].

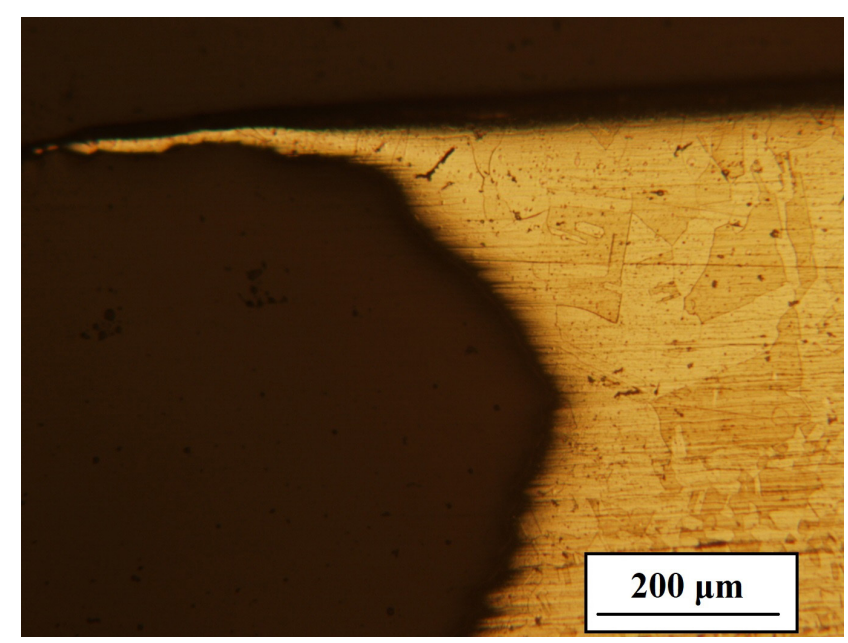

Fig. 6 Pitting in the base material of sample 4

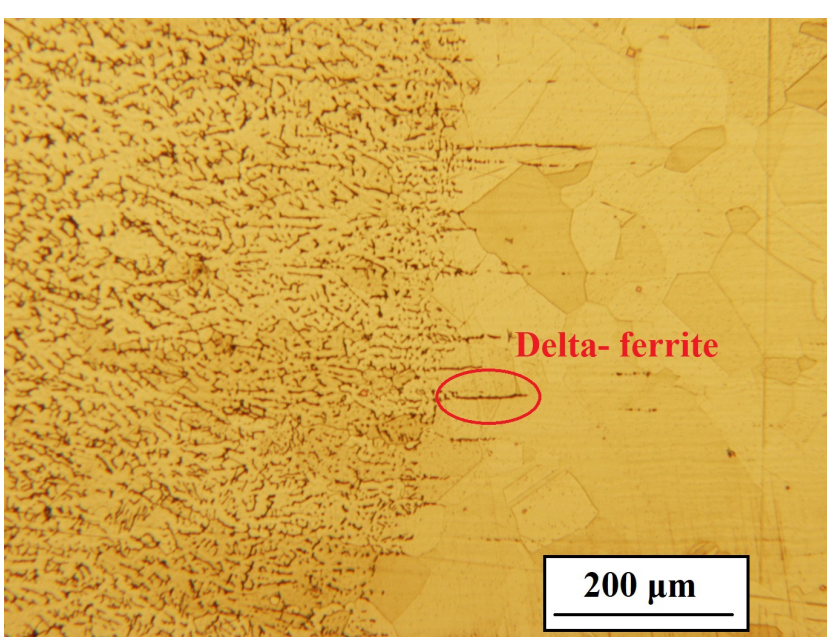

Fig. 7 Delta-ferrite in the HAZ

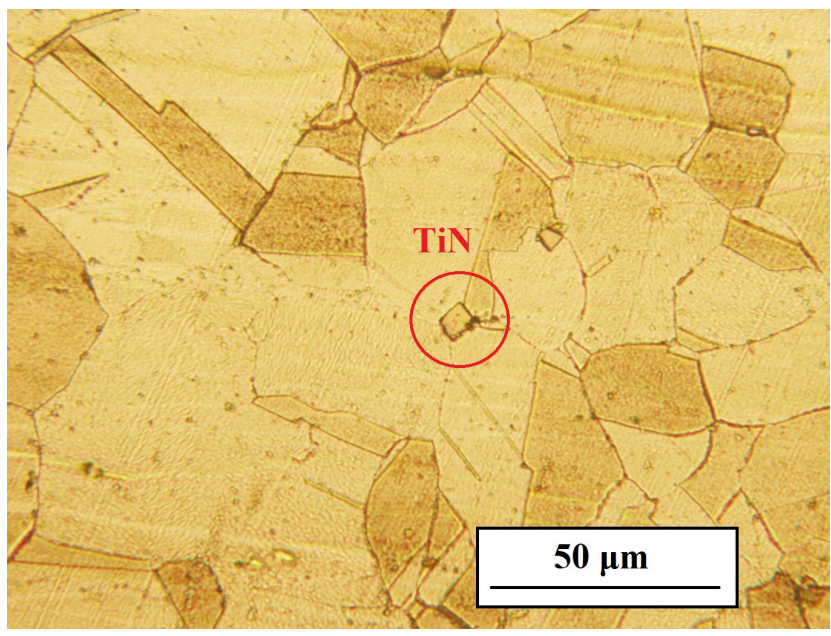

Fig. 8 Microstructure of austenitic stainless steel and the titanium nitride

The EDS measurement was performed in order to ascertain the nature of the precipitation (TiN). An environment full of precipitation can be seen in Fig. 9. The EDS result of

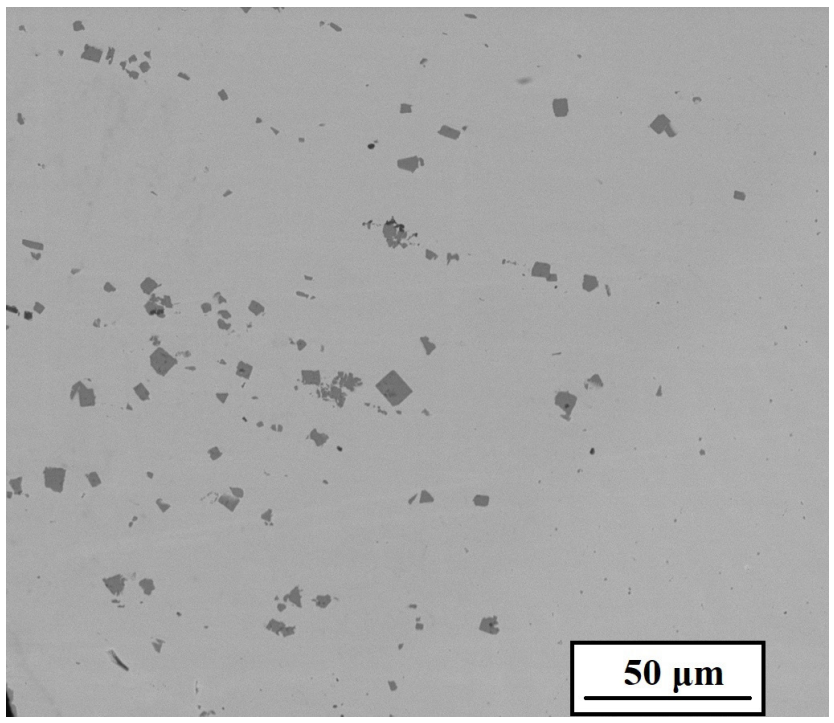

Fig. 9 SEM image of the precipitation (TiN) area 
measured precipitation is the following in weight percent: Fe: $1.61 \%$, Ti: $80.09 \%$, N: $17.67 \%$, Cr: $0.58 \%$, Si: $0.06 \%$.

\subsection{Determination of weight loss and pitting numbers}

The phenomenon of pitting is valued by loss of weight according to the standard. Unfortunately, the evaluation is not accurate because of the specifics of pitting.

Fig. 10 shows that $61 / \mathrm{min}$ gas caused higher weight loss than the $10 \mathrm{l} / \mathrm{min}$ gas quantity (except for $55 \mathrm{~A}$ ). The weight loss was the least at $50 \mathrm{~A}$ for both 10 and $6 \mathrm{l} / \mathrm{min}$ shield gas. It can be determined with the help of bar graphs that the weight loss increases with the growth of amperage.

The pitting numbers on the weld, HAZ, and base material were measured after 24 hours corrosion test. The pitting number as a function of current for 6 and 10 1/min of shielding gas is shown in Fig. 11.

The pitting numbers were decreased with increasing current, and the worst value was at $50 \mathrm{~A}$, as can be seen in Fig. 11.

\subsection{Corrosion rate}

The main purpose of this measurement was to compare the corrosion resistance by two different methods.

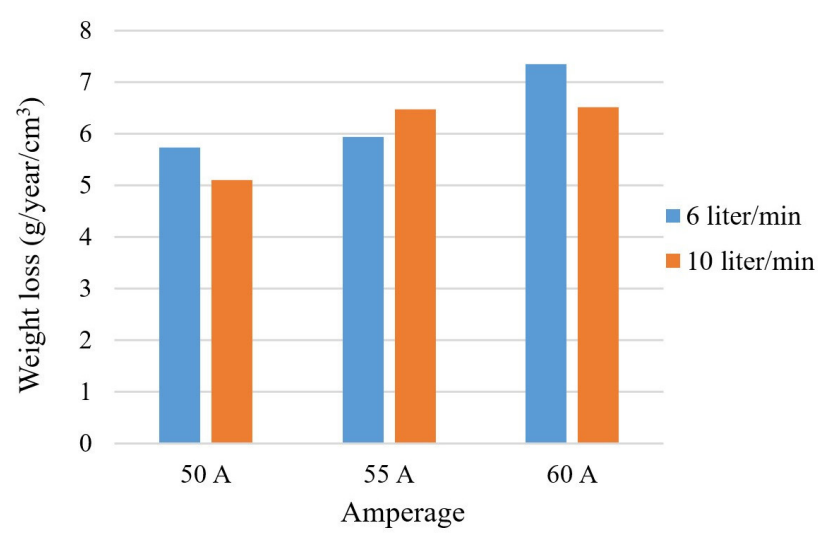

Fig. 10 The weight loss according to the amperage and shield gas

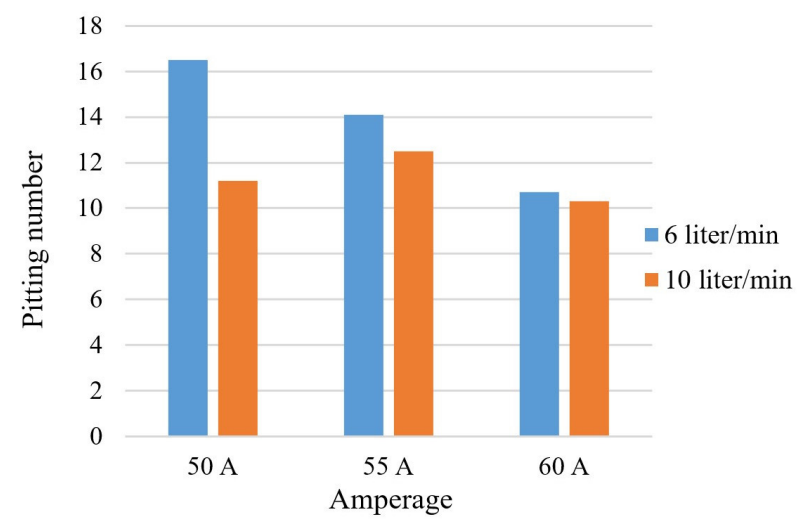

Fig. 11 The pitting numbers according to the amperage and shield gas
The first was the ASTM G48 standard corrosion test, as it was described in the previous chapter, and the second was the potential-difference measurement with Biologic SAS type SP-150 potentiostat. The examined welded joint was made with $50 \mathrm{~A}$ and 10 1/min shielding gas.

Table 4 shows the weight loss due to corrosion. The calculated weight loss was $0.2 \mathrm{~g} /$ year $/ \mathrm{cm}^{3}$.

General corrosion was observed on the entire surface of the sample after the corrosion test. Pitting appeared on the welded joint.

The aim was to determine the potentiodynamic curve and calculate the corrosion rate with 24 hours experiments. The sample was put into the $9 \%$ saline solution. In the beginning and at the end, the difference in the solution can be seen in Fig. 12.

The explanation of the discolored solution is the dissolution of metal $(\mathrm{Fe})$ into the liquid because of the potential difference. The following potentiodynamic curves were obtained (Fig. 13) at the end of the measurement.

It was necessary to measure the weight and atomic percent to determine the corrosion rate. The sample surface was equal by base material, HAZ and welded joint. Consequently, the correct data can be obtained if the average atomic and weight percent of these three areas were used. From these values, the equivalent weight and density can be calculated. The results are shown in Table 5 .

The corroded surface was $139.96 \mathrm{~cm}^{2}$. After software evaluation, the corrosion rate was determined, $0.045 \mathrm{~mm} /$ year in a $9 \%$ saline solution.

\begin{tabular}{lcc} 
Table $\mathbf{4}$ The sample mass before and after corrosion \\
\hline $\begin{array}{c}\text { Before corrosion } \\
\text { test }(\mathrm{g})\end{array}$ & $\begin{array}{c}\text { After corrosion } \\
\text { test }(\mathrm{g})\end{array}$ \\
\hline X6CrNiTi18-10 & 21.9289 & 21.8520 \\
\hline
\end{tabular}
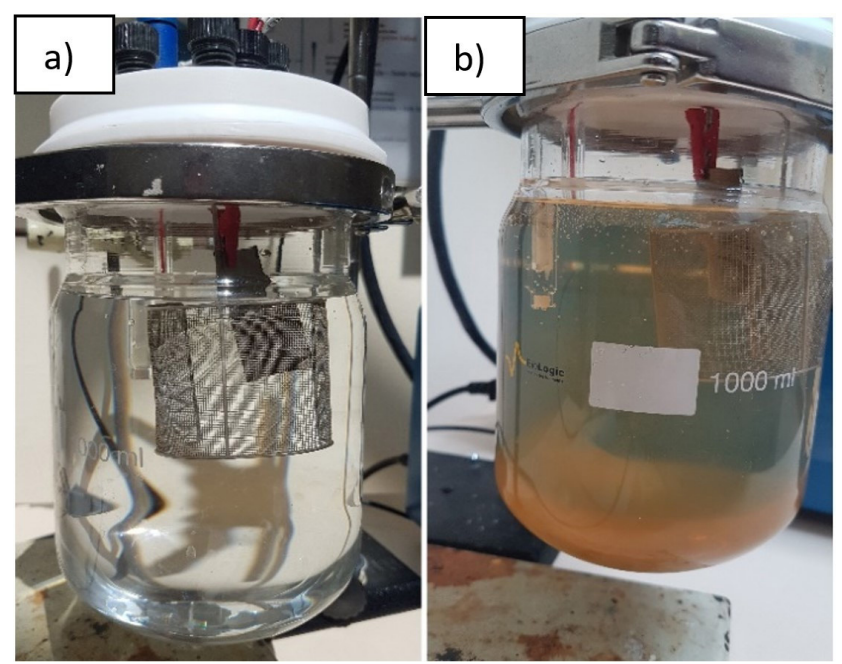

Fig. 12 The solution before a) and after b) corrosion test 


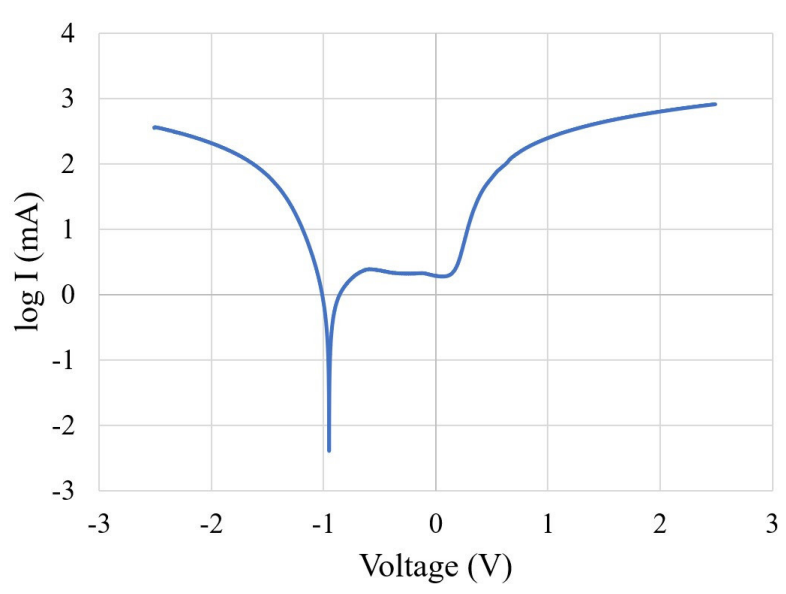

Fig. 13 Potentiodynamic curve of austenitic steel welded joint

Table 5 Calculated results of the sample

\begin{tabular}{lcc}
\hline Sample & Equivalent weight $(\mathrm{g} / \mathrm{eq})$ & Density $\left(\mathrm{g} / \mathrm{cm}^{3}\right)$ \\
\hline Basic material & 18.4424 & 7.7639 \\
Heat affected zone & 18.6114 & 9.9342 \\
Welded joint & 9.6652 & 4.3365 \\
Average & 15.5734 & 7.3449 \\
\hline
\end{tabular}

\section{Conclusions}

Pitting is one of the most dangerous corrosion types, which a very corrosive environment can cause. Pitting sensitivity can be increased by welding, so choosing the right welding parameters is necessary.

Investigations revealed that pitting corrosion was more significant in weld than in the base material. The same phenomenon was observed in the article of Chuaiphan and Srijaroenpramong [26]. Furthermore, the smallest weight

\section{References}

[1] Zaffora, A., Di Franco, F., Santamaria, M. "Corrosion of stainless steel in food and pharmaceutical industry", Current Opinion in Electrochemistry, 29, Article number: 100760, 2021.

https://doi.org/10.1016/j.coelec.2021.100760

[2] Ma, X., Zhao, X., Zhang, Y., Liu, K., Yang, H., Li, J., Akhlaghi, Y. G., Liu, H., Han, Z., Liu, Z. "Combined Rankine Cycle and dew point cooler for energy efficient power generation of the power plants A review and perspective study", Energy, 238(A), Article number: 121688, 2022.

https://doi.org/10.1016/j.energy.2021.121688

[3] Gooch, T. G. "Corrosion Behavior of Welded Stainless Steel: Corrosion resistance of stainless steel weld metal depends on an understanding of the nature of the protective passive film that gives the steel its "stainless" characteristic", Welding Journal, Welding Research Supplement, 75(5), pp. 135-s-154-s, 1996. [pdf] Available at: https://app.aws.org/wj/supplement/WJ_1996_05_ s135.pdf [Accessed: 20 September 2021] loss was associated with a low number of holes which occurred by $50 \mathrm{~A}$ and $10 \mathrm{l} / \mathrm{min}$ shielding gas. Counting the amount of pitting on corroded surfaces the least pitting was measured at $60 \mathrm{~A}$. It should be noted that the least weight loss was at $50 \mathrm{~A}$, but there was the most pitting on the surface. This can be attributed to the nature of pitting caused by $60 \mathrm{~A}$, the number of pitting was less, but it shows much deeper characteristics so that more weight loss can occur.

It can be concluded that based on the ferrite content values, the optimal value is also $50 \mathrm{~A}$ amperage and $10 \mathrm{l} / \mathrm{min}$ shielding gas.

The corrosion rate could be determined as $0.045 \mathrm{~mm} /$ year of the austenitic stainless steel welded joint using a potentiodynamic corrosion test. The amperage and the shield gas were optimal, which is based on previous measurements.

The weight loss was different by the two corrosion tests because of the solution. The Fe(III)-chloride solution is an aggressive corrosion environment, and the weight loss of the samples was about $5 \ldots 7 \mathrm{~g} / \mathrm{year} / \mathrm{cm}^{3}$, and the saline was a less corrosive medium, and the weight loss was $0.2 \mathrm{~g} / \mathrm{year} / \mathrm{cm}^{3}$.

\section{Acknowledgement}

The research reported in this paper and carried out at BME has been supported by the NRDI Fund (TKP2020 IES, Grant No. BME-IE-NAT and TKP2020 NC, Grant No. BME-NC) based on the charter of bolster issued by the NRDI Office under the auspices of the Ministry for Innovation and Technology.

[4] Kalácska, E., Májlinger, K., Varbai, B. "Gas tungsten arc welding of different high strength austenitic stainless steel grades", [pdf] In: $3^{\text {rd }}$ Young Welding Professionals International Conference (YPIC 2017), Halle an der Saale, Germany, 2017, pp. 20-26. Available at: https://www.researchgate.net/profile/KornelMajlinger/publication/319240853_Gas_tungsten_arc_welding _ of_different_high_strength_austenitic_stainless_steel_grades/ links/599d4271a6fdcc50034e3bfa/Gas-tungsten-arc-weldingof-different-high-strength-austenitic-stainless-steel-grades.pdf [Accessed: 30 September 2021]

[5] Kim, E. T., Ishtiaq, M., Han, J. C., Ko, K. K., Bae, H. J., Sung, H., Kim, J. G., Seol, J. B. "Near atomic-scale comparison of passive film on a $17 \mathrm{wt} \%$ Cr-added $18 \mathrm{wt} \% \mathrm{Mn}$ steel with those on typical austenitic stainless steels", Scripta Materialia, 203, Article number: 114112, 2021.

https://doi.org/10.1016/j.scriptamat.2021.114112 
[6] Alcantara, A. S., Fábián, E. R., Furkó, M., Fazakas, É., Dobránszky, J., Berecz, T. "Corrosion Resistance of TIG Welded Joints of Stainless Steels", Materials Science Forum, 885, pp. 190-195, 2017.

https://doi.org/10.4028/www.scientific.net/MSF.885.190

[7] Ohmi, T., Nakagawa, Y., Nakamura, M., Ohki, A., Koyama, T. "Formation of chromium oxide on 316L austenitic stainless steel", Journal of Vacuum Science \& Technology A, 14(4), pp. 2505-2510, 1996.

https://doi.org/10.1116/1.580010

[8] Sunny, K. T., Korra, N. N. "A systematic review about welding of super austenitic stainless steel", Materials Today: Proceedings, 47(14), pp. 4378-4381, 2021.

https://doi.org/10.1016/j.matpr.2021.05.185

[9] Pradhan, S. K., Bhuyan, P., Bairi, L. R., Mandal, S. "Comprehending the role of individual microstructural features on electrochemical response and passive film behaviour in type 304 austenitic stainless steel", Corrosion Science, 180, Article number: 109187, 2021. https://doi.org/10.1016/j.corsci.2020.109187

[10] Tranchida, G., Clesi, M., Di Franco, F., Di Quarto, F., Santamaria, M. "Electronic properties and corrosion resistance of passive films on austenitic and duplex stainless steels", Electrochimica Acta, 273, pp. 412-423, 2018. https://doi.org/10.1016/j.electacta.2018.04.058

[11] Wang, L., Seyeux, A., Marcus, P. "Thermal stability of the passive film formed on 316L stainless steel surface studied by ToF-SIMS", Corrosion Science, 165, Article number: 108395, 2020. https://doi.org/10.1016/j.corsci.2019.108395

[12] Dadfar, M., Fathi, M. H., Karimzadeh, F., Dadfar, M. R., Saatchi, A. "Effect of TIG welding on corrosion behavior of 316L stainless steel", Materials Letters, 61(11-12), pp. 2343-2346, 2007. https://doi.org/10.1016/j.matlet.2006.09.008

[13] Kumar, S. S., Murugan, N., Ramachandran, K. K. "Microstructure and mechanical properties of friction stir welded AISI 316L austenitic stainless steel joints", Journal of Materials Processing Technology, 254, pp. 79-90, 2018. https://doi.org/10.1016/j.jmatprotec.2017.11.015

[14] European Steel and Alloy Grades/Numbers Searchable Database "X6CrNiTi18-10 (1.4541)", [online] Available at: http://www. steelnumber.com/en/steel_composition_eu.php?name_id=102 [Accessed: 30 September 2021]

[15] Dak, G., Pandey, C. "Experimental investigation on microstructure, mechanical properties, and residual stresses of dissimilar welded joint of martensitic P92 and AISI 304L austenitic stainless steel", International Journal of Pressure Vessels and Piping, 194(A), Article number: 104536, 2021. https://doi.org/10.1016/j.ijpvp.2021.104536

[16] ASTM International "ASTM G48-11(2020)el Standard Test Methods for Pitting and Crevice Corrosion Resistance of Stainless Steels and Related Alloys by Use of Ferric Chloride Solution", ASTM International, West Conshohocken, PA, USA, 2020. https://doi.org/10.1520/G0048-11R20E01
[17] Carpén, L. "Corrosion of Stainless Steel in Fire Protection Systems", [pdf] VTT Technical Research Centre of Finland Ltd., Espoo, Finland, Rep. VTT-R-01556-08, 2008. Available at: https:// www.vttresearch.com/sites/default/files/julkaisut/muut/2008/ PALOMICTutk_rap_final.pdf [Accessed: 30 September 2021]

[18] Pandya, D., Badgujar, A., Ghetiya, N. "Effect of hydrogen additions to shielding gas on activated TIG austenitic stainless steel weld", Materials Today: Proceedings, 47(4), pp. 1025-1029, 2021. https://doi.org/10.1016/j.matpr.2021.05.569

[19] Garcia, C., Martin, F., de Tiedra, P., Blanco, Y., Lopez, M. "Pitting corrosion of welded joints of austenitic stainless steels studied by using an electrochemical minicell", Corrosion Science, 50(4), pp. 1184-1194, 2008. https://doi.org/10.1016/j.corsci.2007.11.028

[20] Jiménez-Come, M. J., Muñoz, E., García, R., Matres, V., Martín, M. L., Trujillo, F., Turias, I. "Pitting corrosion behaviour of austenitic stainless steel using artificial intelligence techniques", Journal of Applied Logic, 10(4), pp. 291-297, 2012. https://doi.org/10.1016/j.jal.2012.07.005

[21] Malik, A. U., Al-Fozan, S. A. "Pitting Behaviour of Type 316L S.S in Arabian Gulf Seawaterl", Saline Water Conversion Corporation (SWCC), Riyadh, Saudi Arabia, Rep. SWCC (RDC)22, 1992. [online] Available at: https://www.researchgate.net/ publication/242118809 [Accessed: 30 September 2021]

[22] Varbai, B., Pickle, T., Májlinger, K. "Development and Comparison of Quantitative Phase Analysis for Duplex Stainless Steel Weld", Periodica Polytechnica Mechanical Engineering, 62(3), pp. 247-253, 2018. https://doi.org/10.3311/PPme.12234

[23] Singh, S., Hurtig, K., Andersson, J. "Investigation on effect of welding parameters on solidification cracking of austenitic stainless steel 314", Procedia Manufacturing, 25, pp. 351-357, 2018. https://doi.org/10.1016/j.promfg.2018.06.103

[24] Bödök, K. "Gőzfejlesztő hőátadó csövek külső, szekunderköri oldalán észlelt korróziós termékek és lerakódások eddigi vizsgálati eredményeinek összefoglaló elemzése" (Summary analysis of previous test results of corrosion products and deposits detected on the outer secondary circuit side of steam generator heat transfer tubes), Corweld Kft., Budapest, Hungary, 2004. (in Hungarian)

[25] González, M. P. V., González Meije, A., Muro, A. P., GarcíaMartínez, M., Caballero, B. G. "Failure analysis of a fuel control pressure tube from an aircraft engine", Engineering Failure Analysis, 126, Article number: 105452, 2021. https://doi.org/10.1016/j.engfailanal.2021.105452

[26] Chuaiphan, W., Srijaroenpramong, L. "Microstructure, mechanical properties and pitting corrosion of TIG weld joints alternative low-cost austenitic stainless steel grade 216", Journal of Advanced Joining Processes, 2, Article number: 100027, 2020. https://doi.org/10.1016/j.jajp.2020.100027 